\title{
A Study on CPH and Debate Summary in FLL
}

\author{
Zhiliang Liu \\ Foreign Languages Department \\ Beihai College of Beijing Aeronautics and Astronautics University \\ PO box: No 88 Silver Beach Boulevard, Beihai 536000, China \\ E-mail: zlliuman@yahoo.com.cn
}

The research is financed by the National Basic Foreign Language Teaching Research Center of China. No. JJWYYB2006114

\section{Abstract}

The optimal age in FLL (foreign language learning) for children has been discussing over 50 years but there is no satisfactory conclusion for us. However, the notion "the younger, the better" in FLL has a big market in the world. As a result, the distorted hypothesis is being spreading widely as a true and complete theory. Specifically speaking, it's caused by the confusion on the concepts of "second language and foreign language", "learning and acquisition", "CPH (critical period hypothesis)". Therefore, based upon the discussion of theoretical foundation of linguistics, psychology and physiology in FLL for children, the environment of FLL and the importance of mother tongue, all of us will have a complete knowledge of the concept. By analyzing the deep reasons on the tendency of lowering the age in FLL both at home and abroad, those blind followers who are still being misled will have a rational attitude towards FLL. Hence, the rational deeds of "a language can be taught from any age upwards" will definitely go into the heart of everyone.

Keywords: Optimal age, Second language \& foreign language, Learning \& acquisition, CPH

\section{Introduction}

The starting age of foreign language learning for children has been discussing over 50 years worldwide. It had also been discussed twice both in the $80 \mathrm{~s}$ and $90 \mathrm{~s}$ of the $20^{\text {th }}$ century in China. However, there is no satisfactory conclusion for us. English course began to be offered gradually in elementary schools in China from the fall of 2001, while the notion "the younger, the better" in learning a foreign language is believed without any doubt by many people. In view of this situation, based upon the analyses on the theoretical foundation of linguistics, psychology and physiology in FLL for children, the environment of FLL as well as the importance of mother tongue, we put forward only a few comments and suggestions on the tendency of lowering the age in FLL in China presently. By doing so, we are expecting to get some substantial conclusions from the analyses, which can be of some benefit to FLL for children, so as to face the realistic problem of "FLES (Foreign Languages in Elementary Schools)" with a rational attitude.

\section{Clear-up of the key terms}

\section{1 Acquisition vs learning}

Krashen uses the term 'acquisition' to refer to the spontaneous and incidental process of rule internalization that result from natural language use, where the learner's attention is focused on meaning rather than form. It contrasts with 'learning' (Ellis, 1999, p.692).

Krashen uses the term 'learning' to refer to the development of conscious knowledge of an L2 through formal study. It means the same as explicit knowledge (ibid). In this process, the learner's attention is focused on form rather than meaning.

The language gained through learning can neither be changed into the knowledge of language acquisition system nor express the speaker's meaning in the natural situation of communication, but only elaborate the function of 'monitoring'. 'Monitoring' is the learner's conscious supervision over the quality of his own language output, which occurs before, after or during the process.

Language learning refers to the mastering of the language through language teaching, while language acquisition is the grasping of the language by natural, random and quantity times of contacting with the language (Wilkinson, 1990, p.38).

\subsection{Second language vs foreign language}

In a broad sense, second language refers to a language beyond mother tongue or first language (Ellis, 1999, p.692). This definition emphasizes the general character of all languages except mother tongue. However, foreign language is 
different from second language in the essence.

Stern (1999, p.366) discusses the differences between foreign language and second language from the aspect of their language function, learning aims, language environment, learning methods and the like. 'Second language' is opposite to 'first language', while 'foreign language' and 'non-native language' are opposite to 'mother tongue' and 'native language'. 'First language', 'mother tongue' and 'native language' are of one group, while 'second language', 'foreign language' and 'non-native language' of the other.

Second language often has the official status and established social function in its local place, while foreign language does not. The aim of learning a second language is to take part in all-round political and economic activities in the country the language belongs to, while the aim of learning a foreign language is for traveling, communicating with native speakers, reading foreign literature and scientific documents. In learning a second language there is a sufficient language environment, while there are few chances and places of contacting with the foreign language except the limited classroom teaching and several copies of textbooks. Foreign language teaching is often in the classroom, while second language learning doesn't need any formal classroom teaching but usually acquired in natural environment.

In my understanding, TESL (teaching English as a second language) is the kind of teaching to teach and learn a language with the language environment itself, but not the learners' native language. For example, when we Chinese go to the USA or Britain to study or work there, we have to learn English so as to live and communicate with the local people. Such kind of teaching should be called TESL. Another important sign is whether it is TEFL (teaching English as a foreign language) or TESL depends on the teaching language of other subjects used in the school. If their teaching language is their mother tongue or they teach the subjects chiefly in their mother tongue, then the English teaching should be called TEFL. Obviously, English teaching in China is TEFL.

Instead of being acquired, English can only be learnt in China, therefore it's very difficult.

\section{Literature review of FLES}

\subsection{A General introduction to the study of age in FLL abroad}

It seems that it's a common sense for everyone that children have dominant superiority in FLL. But what are the theoretical basis and the experimental foundation for the cognition? Concerning the issue of age in FLL, many fields of science like psycholinguistics, neuro-linguistics, cognitive linguistics, socio-psychology, pedagogy, linguistics, the science of human brains and others have to be dealt with, therefore, it is a real complex problem. From the relative researches and experiments, we can see clearly that most of the researchers admit that there is a critical period in acquisition or learning of an L2 instead of a foreign language, but disputes still remain on the recognition of this issue.

Actually, age doesn't make up the dominant superiority in foreign language learning until it is combined with the other factors, only by doing so can it produce effect and elaborate its superiority. The important factors among the factors mentioned here are the guarantee of the quality of teaching, enough learning time and the setting-up of the language environment. In other words, FLL in the earlier age for children cannot guarantee their language superiority except that there are painstakingly designed courses, higher quality teachers and favorable environment for FLL.

We are facing different kinds of difficulties and problems of the research on the issue of age and FLL as there are so many factors affecting the results of it. As a result, there has been no agreement on the research of optimal age in FLL so far. (Nikolov M, 2000, p.21-48) In a word, the process of cognition has been experienced repeatedly in the following stages.

\subsection{Previous research into FLES abroad (Huanqi Zuo, 2002, p.36-40)}

\subsubsection{First stage}

From 1940s to 1960s, there's a strong view both in theory and practice that the starting age of foreign language learners should be shifted to a younger one. Neuro-physiologists like W. Penfield and L. Robert emphasized that the starting age of foreign language learners should be from 4 to 10 years old in ordinary schools according to the demands of brain psychology. E. Lenneberg put forward the famous "critical period hypothesis" in 1967 that natural language learning only took place between the ages of 2 and 13 or so (before puberty). Based on these theories, the upsurge of FLES occurred in the USA. Foreign languages were taught from grade 3, 4 or 5 in most elementary schools and even in some kindergartens there, too. For a time, FLES had become a special term and subject in the circles of linguistics and education. At the same time, the experiment of shifting to a younger age in foreign language teaching began in Britain, France, Germany, Switzerland, Holland and so on.

\subsubsection{Second stage}

After a period of practice and experiment, the upsurge of FLES has begun to fall back to its original state since 1970s. The most important reason was they were short of qualified teachers, good textbooks. Therefore, teaching quality was far from expected. As early as in 1963, the British Educational Department organized a ten-year experiment (1964-1974) 
in Scotland and Walsh. The results were: Those didn't take part in the experiment but began to learn French at the age of 11 had better results than those did it at the age of 8 , when graduating from secondary schools. Thereafter, quite a few experiment reports, like the ones from the USA, Denmark and so on indicated the students began to learn foreign languages in secondary schools and those had done them for 11 years from elementary schools both reached the same level. In theory research, the "critical period hypothesis" raised by E. Lenneberg was doubted at the same time. The main basis of the "critical period hypothesis" was that one couldn't learn a foreign language well after the brain lateralization before one's puberty. But the experiments by Krashen and some other experts proved the brain lateralization possibly completed before 4 years old. As a matter of fact, foreign languages could still be learnt well after 4 years old. T. Scovel thought different people had different brain lateralization, for there's no same "critical period". Thereafter, linguists and child language researchers all considered that age wasn't as important as people imagined, for there were many factors affecting FLL. In the mid-1990s, the percentage of schools of FLES was only $26 \%$ among the total in the USA.

A. Fathman and Krashen's viewpoints reflected mainly the opinions of the researchers' on the problem of age in FLL during that period. In 1975, A. Fathman made an investigation on the mastering of English of the immigrants' children (about 200) in Washington D.C. These children had been in the USA for less than 3 years and they didn't speak English at home. The result of the investigation indicated that older children (11-15y) did better than younger ones (6-10y) on words and sentences, but the latter did better on pronunciation. After the summary of the others' research results, Krashen pointed out that, comparing adults with children, older children with younger ones, the former of the two groups both developed faster in learning words and sentences, however, in a natural language environment, children had a higher level than adults in mastering an L2 in the end. (Krashen, 1982, pp.120-129.)

\subsubsection{Third stage}

Since 1990s, some new phenomena have been found in the research of bilingual education, that is, some less than 7-year-old children had an active attitude toward an L2 and its culture after having received the bilingual education. These attitudes both pushed them forward in learning an L2 and made them get better results. Meanwhile, when the children began to learn an L2 before 7 years old, they could have natural pronunciation and intonation as the English native speakers' when they became adults. When they began to learn English after 14 years old, they often had their L1 accents. When they began to learn English from the ages of 7, 14 or 15, their English was quite different from one another. This phenomenon indicated that, just as the research results made by A. Fathman and Krashen, those began to learn an L2 from a younger age in their childhood could at least have better pronunciation and intonation than those didn't. These phenomena changed the viewpoints on the starting age in teaching an L2 in some countries. Taking Holland for example, it decided to teach English in elementary schools again and have already financed much in training English teachers.

Stern drew a conclusion (Stern, 1999) that "a guiding principle arrived at after a review of much of the available evidence (Stern \& Weinrib, 1977, p.20, 1978, p.167) has been 'to recognize that a language can be taught from any age upwards. Once this has been accepted, the decision at what stage in the educational process to introduce a foreign language can be governed by three criteria: (a) the estimated time necessary to reach a desired level of language proficiency by a specified stage in the school career of the majority of learners; (b) the educational value attributed to learning foreign languages at a given stage of the curriculum; and (c) the human and material resources required to develop and maintain an educationally sound and successful foreign language program.' "'

In a word, the repetitive cognition on the starting age in learning an L2 gave us proof that it's really a complicated problem. When to begin foreign language teaching in elementary schools should be decided step by step according to the experiments by researchers for a long time. To begin FLES too early and without qualified teachers or good textbooks, it couldn't make a better foundation for the pupils in learning an L2. What's worse, it would affect their level of L1 in their future adult life and this kind of loss would be irreparable.

\subsection{Previous research into FLES in China}

\subsubsection{A brief history of FLES since the early 1960s}

\subsubsection{First stage}

Early in the 1960s, the streamline of foreign language teaching from elementary school to university was advocated greatly, but it only started in a few affiliated schools to some foreign languages institutes, and there were about 14 such schools set up in big cities like Beijing, Shanghai and so on. Most of the pupils were selected from grade 3 in many elementary schools in big cities according to their scores of maths and Chinese. (Ke Fu, 1987, p.66)

\subsubsection{Second stage}

In 1976, everything was taking on a new look in China and FLES began nationwide. Unfortunately, it was abandoned in the early 1980s hurriedly. The main cause was due to the lack of qualified foreign language teachers, suitable textbooks, 
educational research, and the problem of teaching connection between elementary and secondary schools. However, people in the cities of Shanghai, Beijing and so on, kept on teaching English in elementary schools for they had better teaching conditions. (Daoyi Liu. 2001, Issue 8)

\subsubsection{Third stage}

Since the late 1980s, due to the policy of reform and opening-up-to-the-outside-world, FLES began to be advocated again nationwide, therefore causing debates at the same time among scholars and researchers. Finally, the decision of offering English courses, from grade 3 in elementary school in the fall of 2001, was made by the Chinese Ministry of Education. Though it kept up with the trends of FLES in the world, yet brought greater debates on the issue. This time many famous scholars and researchers took part in it by writing papers and articles in magazines and newspapers, thus, forming 3 kinds of viewpoints.

\subsubsection{Three kinds of viewpoints on FLES in China}

\subsubsection{First kind}

Many experts and researchers hold the viewpoints that it's not necessary to offer foreign language courses to children nationwide without enough qualified teachers, suitable textbooks or other teaching equipment. They disagree to the idea "the younger, the better" in FLL.

Guozhang $\mathrm{Xu}$ once said in a magazine. "A piece of news was reported on the front page in Guang Ming Daily that there's an experiment of education in Shanghai. The main meaning is that a private school is opening up there, and it will enroll new students by its own without any national examinations. The pupils in this school are beginning to learn a foreign language from elementary school, and will go on to learn another one when they are in junior middle school. Concerning the pros and cons of the national examinations, we shouldn't make any casual remarks about them. But talking about FLES, I have got a good lesson. English course covered most of the time during my 5 years' study in elementary school. We had learnt altogether about 160 articles in the 5 years, one each week on average. And the texts had been rewritten over and over again. As a result, they became the articles of only sentences without literary grace, only texts without feelings. We did recite each one of them, but we still couldn't get the real or lively English. Besides, pupils were made to pay special attention to English, as a result, our mother tongue---Chinese was reduced and affected much as a whole. Now pupils and students have to learn English for 11 years from elementary to secondary schools in some attached schools of universities, dealing with short articles is the main activity in their learning, which is very drab and dull. From this you can see how the pupils' appetites spoiled in the attached schools. I don't know what the reformers think about the above. But I wish that the reformers should have their eyes on the basis of our own language and culture before all the others, and still I'd like to suggest that English, Chinese and mathematics should be paid attention to on average."

Concerning the problem of FLES, Shichun Gui (1987, pp.56-57) had some doubts on it in one of his articles. It said that the result of the present modes of English teaching both in elementary and secondary schools were not satisfactory. Students had spent 6 years in learning English (about 900 hours) in secondary schools, as a result, they could only know a little bit of grammar and remember about 1,800 words, let alone their bad language ability. From the perspective of educational economy, the loss outweighed the gain. This was due to the traditional idea that FLL should be started from a younger age, as for the time, the longer the better. However, the problem of the other side of it had been neglected. This kind of situation was especially serious in China.

Gui presented his ideas in one of the Foreign Language Teaching Seminars in 2003 that "Days ago Professor McWhinney, a psychologist, of the University Carnegie-Mellon came to Guangzhou to give a lecture, he asked me 'why do the schools both in Taiwan and the mainland go in for offering English course in elementary schools?' It's very hard for me to give him a satisfactory answer. To offer English course in elementary schools is a policy made by the Chinese Ministry of Education, but I don't know how this policy was made. At the beginning, English course was offered from grade 5 in elementary schools, later from grade 3 and now grade 1. In Guangdong province, many elementary schools began to offer it from grade 1, some even did it from kindergartens, what's worse, some even from the babies in their mothers' wombs just because it's said that they should learn English before they were born. In a word, it's just because of the so-called common sense that 'the earlier, the better' in learning a foreign language. Actually, two international conferences were held on FLES in Hamburg Germany after World War II in 1962 and 1966 sponsored by the UNESCO (the United Nations Educational, Scientific and Cultural Organization), specially discussing the issue of whether or not to offer a foreign language course in elementary schools. Finally, a conclusion was drawn by Carol, a psychologist from the USA, saying that 'there is no satisfactory answer to it' on the issue of whether children do better and faster than adults in learning a foreign language. Besides, there are some other conclusions. 1) Does it have any effects on other subjects? According to those attendants, there are some effects, but not very much. 2) Pronunciation level of those earlier foreign language learners would be trained near that of the native speakers'. These two points seem to support the notion of FLES, but there are some opposite viewpoints at the same time. First, FLES is really good to 
the pronunciation. However, other abilities such as vocabulary, grammar and the like would grow with the growth of age even up to one's twenties except pronunciation, which has something to do with the development of cognition. Second, although pronunciation really benefits from FLES, yet curriculum of not even one country required the pupils to raise their pronunciation level near that of the native speakers' at that time. Third, to reach this level, teachers must be the native speakers. If not, how could they train their pupils' pronunciation level near that of the native speakers'. From the condition of that time in the world, it's impossible for all the elementary schools to employ the teachers from English-speaking countries. Till the end of the two conferences, FLES in all countries was still in the experimental stage. Not even one country said that it would spread it nationwide. I think this is a wrong way in FLL. Experiments could be done, but we shouldn't call all the schools to do it without considering their real conditions. Once I talked with the makers of the curriculum. I asked them: 'Have you ever done any survey in the backward areas in the mountains?' In those areas, the secondary schools are short of English teachers, let alone the elementary schools. They said 'yes'. 'Then, why did you put forward the idea of FLES in the curriculum?' I asked. They said that the curriculum should be elastic and advanced. To carry it out or not is another matter. But first we must put it forward. It doesn't matter whether the school couldn't do it or not. This is another wrong way in making the curriculum. Since the curriculum is elastic, and to carry it out or not is of no importance, then, what's the use of making such a curriculum?"

Besides, who would teach the pupils when starting learning foreign languages in elementary schools nationwide? Where could we find so many qualified teachers?

As far as the shortage of qualified teachers is concerned, Zhengdong Zhang said that "there are 500 thousand secondary school teachers of English now, but we need 3 times as many as those of elementary school English teachers, that is, 1.5 million, at least 1 million must go to the posts". (Zhengdong Zhang, 2001.3.1) "It's known that the time of training a qualified teacher will spend 3 years at least." (Daoyi Liu. 2001, Issue 8) Where can we find so many qualified teachers in such a short time? If we let the unqualified teachers go to the posts, the result will be from bad to worse. If we go on doing it this way, more and more losses will be cost both in human forces and material resources.

Taking the English words for example, 3000-4000 words must be mastered during the basic education period, that is, for the students from grade 1 to grade 12 according to the New Standards of English Course for Basic Education made by the Chinese Ministry of Education in 2001. Thus, 600-700 words must be mastered during the years from grade 3 to grade 6 in elementary school. This number of words is the same amount as that for junior 1 to 3 in the 1980s. A nationwide survey of the graduates from junior middle schools made by the Association of TEFL in Northwest and Southwest of China in 1997 showed that each student spent 9 hours a week on English course both in and out of class, that is, 540 minutes per week. (Zhengdong Zhang, 2001.3.1) Now there are long and short classes in elementary schools, and there are altogether 4 classes per week. It's estimated that there are 120 minutes in school, even if we add another 120 minutes after school, there are altogether 240 minutes. Comparing with junior middle school students, how could the elementary pupils learn English well in such a short time?

The State Education Commission organized a nationwide survey on English teaching, 15 provinces and cities involved, including 57,080 senior and junior grade 3 students from 139 middle schools in 1985 . The results showed that among the students who had learned English in primary schools, some results are very good, such as the cities of Shanghai and Guangdong, ranking the first and the third respectively. But some results are not ideal, such as the cities of Beijing and Tianjin, which are significantly lower than those of the students who began to learn English from junior grade 1 in middle school from Jilin, Anhui and Hubei provinces.

In 2003, the research on age and FLL was done in Dingfang Su's research project of "English Language Teaching Theory and Practice" sponsored by the Chinese Ministry of Education. It's a survey on the successful experience of the renowned foreign language scholars and the learning results of the students studying German. The results showed that the starting age in FLL isn't "the younger, the better". People, from 20 to 30 years old, can achieve the same good results as those who start FLL from an earlier age. Stern's view that a language can be taught from any age upwards was proved right again. Learning successfully or not depends much on the quality of teachers, the learning environment and personal effort.

\subsubsection{Second kind}

Among the scholars, who are in favor of the decision, Lin Chen is the chief representative. It is clear that the ideas of this kind are based mainly on the conditions that there are qualified teachers of English, suitable textbooks and good teaching equipments. In other words, it can be done only in the schools with good teaching conditions, while in the backward areas it is very hard to carry it out.

Chen Lin presented his ideas in one article that in order to improve the foreign language level nationally, something must be done from the stage of basic education.

In answering the question of "Will the elementary pupils be loaded with much more after offering English course since they have already been loaded with much?" Chen's reply is: "Both 'yes' and 'no'. But it all depends on man. This 'man' 
is teacher. So we should say that 'It all depends on teacher.'"

In a word, as long as the contents and methods of English teaching can arouse children's interest, it will open the door of a new world for them, thus, making them not only stand outside of the gate peeping inside curiously but also go inside to have a thorough look. Let us give the key to the door to children as soon as possible.

\subsubsection{Third kind}

Some scholars keep an attitude of eclecticism, whose viewpoints are solving the problems in the process of teaching and Zhuanglin $\mathrm{Hu}$ is the main advocator. He said many university students in the past years still had some difficulties in learning a foreign language, though having spent much time on it. As a result, time was overused on foreign language learning, and to some extent, their major studies were affected at the same time. Now the students' foreign language level has been improved steadily on average, which is due to the emphases both from basic and family education. At present, elementary schools nationwide are actively preparing to offer foreign language courses and this should be approved. But much attention should be paid to choosing textbooks by experts' assessment. Concerning the inadequacy of foreign language teachers, He suggested no matter what kind of difficulties lying in front of us, we should offer the courses firstly in the places with well-equipped conditions, while the backward areas should do their best to catch up with the former gradually. All the problems can be solved and the teaching level will be improved little by little. All the weaknesses can be counteracted and the inadequacy will be made up for step by step through teachers training, which should be strengthened.

\section{Related Theories on FLES}

\subsection{Critical period hypothesis}

It states that there is a period (i.e. up to a certain age) during which learners can acquire an L2 easily and achieve native-speaker competence, but after this period L2 acquisition becomes more difficult and is rarely entirely successful. Researchers differ over when this critical period comes to an end (Ellis, 1999, p.712). In other words, there is a widely held lay belief that younger L2 learners generally do better than older learners. This is supported by the critical period hypothesis, according to which there is a fixed span of years during which language learning can take place naturally and effortlessly, and after which it is not possible to be completely successful. Penfield and Roberts in 1959, for example, argued that the optimum period for language acquisition falls within the first ten years of life, when the brain retains its plasticity. Initially, this period was equated with the period taken for lateralization of the language function to the left side of the brain to be completed. Work on children and adults who had experienced brain injuries or operations indicated that damage to the left hemisphere caused few speech disorders or loss of linguistic capabilities and was rapidly repaired in the case of children before puberty (about 12 year-old) but not adults (Lenneberg, 1967, p.66).

Children can communicate with others during their first few years since coming to this world and these years are "the critical period" of their language development. This is taken as the universal truth. In fact, it's mistaken or at least misunderstood. The reason is that infancy has been mistaken as the critical period of language development without explaining clearly that it's the case for one's mother tongue, not for the other languages. The reason children can communicate with others during their first few years since coming to this world is that they speak in their mother tongue, and it's the language they use in their daily life not the other languages beyond their life.

Strictly speaking, mother tongue can't be taught or learnt, but acquired or developed in the environment of their native speakers.

This idea had already been raised by some famous educators. Taking the Italian educator Maria Montessori for example, she thought that child language can't be taught but developed and its development is just like the natural creation. Meanwhile, it follows the innate rules (LAD, i.e., Language Acquisition Device) suitable for all children. The language she mentioned here is the natural language in children's daily life, that is, their mother tongue. Chomsky (1995, p.186), stated the same point of view, but it's much more systematic with the background of linguistic philosophy and linguistic psychology. He thought that language couldn't be taught or learnt, either. Living in an unorganized language environment without any training, or any special language direction, children could still develop their language themselves. He once said that the expression "learning language" could be easily misunderstood. It would be more suitable to use "grammar growing" instead of "learning language". He considered language a kind of "body organ" just like the other organs. So language also has a growing and developing process, which is quite natural and believable. As long as the language environment is natural, any child can develop its language naturally. What we need to point out here is that the language Chomsky referred to is one's mother tongue.

Now we can see that both Chomsky and Montessori considered that language could be developed naturally in the environment and culture of one's mother tongue, which has already been accepted by people without any further proof.

\subsection{Non-critical period hypothesis}

In 1978, C. Snow and her colleagues did a thorough research on the critical period hypothesis. In her article Age 
Differences in Second Language Acquisition, C. Snow gave her all-round commentary about the research. The researchers took the Dutch language learners of different ages whose mother tongue is English as the experimental subjects, and did longitudinal research on their language acquisition activities in the natural environment. Finally, they found that the research subjects between the ages of 12 and 15 and those of adults grasped the Dutch language quickest at the beginning months of the acquisition. But after one-year-study, the research subjects between the ages of 8 and 10 , 12 and 15 mastered the Dutch language best while the children between the ages of 3 and 5 did worst in all the tests. This result of their research denied the critical period hypothesis.

The experiment of age affecting FLL is being done everywhere from time to time in the world. Whether it is the critical period hypothesis or the non-critical period hypothesis, we know what they are experimenting on is not language learning but language acquisition from the perspective of foreign language definition. What they are experimenting on is not FLL but second language acquisition. For this reason, whether there is critical period or not in foreign language learning, all of the research is still unbelievable to us, that is to say, we still can't be convinced by all of their research and experiment now. In other words, no final conclusion has been reached on this matter in the whole world of linguistics and therefore it's still an open hypothesis. But there is one agreement to us all: Early starters can gain better pronunciation and intonation and some of them can even get closer to that of the native speakers'. However, when children surpass their puberty, it's very hard or impossible for them to do so. But what we should notice is that there are some certain conditions for children to elaborate the superiority of their powerful imitation ability. In other words, if children want to develop their pronunciation and communication skills better, they must have better teachers on these aspects. (Xiaodong Liu, 2002, p.31-40) "Otherwise, children could only imitate and get the non-standard pronunciation or nondescript expressions in spoken language (Shichun Gui, 1992, p.54)”.

In China, English is the main language in foreign language teaching. It's known that it's difficult for us to learn English well for it doesn't exist naturally in our daily life as our mother tongue does. Our culture isn't encoded by it. Thus, it can't be used as the tool of communication or thinking. It can't be developed the way our mother tongue---Chinese does, growing day by day. So English has to be learnt, not acquired in China. Mother tongue is developed naturally with the natural language background, so it does have a critical period of development. But, English learning is a kind of man-made process of learning for us, and it has no natural developing process. Therefore, it has no critical period of development, either.

What we should notice is that it's improper to connect the critical period with FLL. There's little bilingual environment in China, so foreign languages can't be developed naturally here.

\subsection{Piaget's theory on child language learning}

The psychologist, Piaget, divided the development of children's cognitive ability into 4 stages in 1971: 1) the stage of mental perception ( $0-2$ years old); 2 ) the stage of pre-operation (2-7 years old); 3 ) the stage of concrete operation (7-11 years old); 4) the stage of formal operation (above 11 years old). In his opinion, children of the second stage (2-7 years old) tend to use only one language. If they learn a second language during this period of time, they will not only get certain setbacks to some extent, but also express their thoughts in the two mixed languages, which have no good to the development of children. (Dan Li. 1987, pp.119-159)

At present, children at the second stage, belonging to an inferior state in FLL, go to elementary school at the age of 6 or 7 in China. Pupils begin to learn Chinese pinyin from the beginning of grade 1 in elementary school, which means they will learn the 56 phonetic symbols and their combination. It'll cause pupils' confusion between English letters (26), English phonetic symbols (48) and Chinese pinyin (56), altogether 130 similar letters in the beginning years of elementary schools. In such a case, if they are made to learn English, it's really hard for them to undertake the difficult job beyond their ability.

\subsection{Importance of mother tongue}

Sizhong Zhang (Xiongli Yang, 2001.11.21)) expressed his ideas that disadvantages outweigh advantages in bilingual language teaching for children. He added only if you have mastered mother tongue well could you really master a second language completely. During his 30 years of foreign language teaching, Zhang found students who are able to master one or several languages proficiently must have already had a solid basis of mother tongue. The reason is during the students' learning of their mother tongue they've already formed a solid basis of thinking and logic ability as well as a powerful understanding of it. Besides, the better level of one's mother tongue and its composition ability can help a lot in FLL. On the contrary, during the childhood, how can children learn a second language well without the language environment before they have mastered their mother tongue? Learning by rote is bound to bring about the psychological factor of inverse reaction for children.

Many scholars have made similar remarks as Sizhong Zhang's. Naiqiang Yao (1996, p.155) recalled that Guozhang Xu once said some Chinese students' oral English is very fluent, their pronunciation and intonation are also quite standard. They can speak endlessly in English and feel pleased with themselves, but their Chinese is poor and they pay little 
attention to the improvement of their culture accomplishment. Frankly speaking, these people are half foreigners at most. He told me repeatedly that being a good English teacher you must have a rich command of cultural accomplishment, especially having a solid foundation of Chinese culture. Only if you have a solid foundation of Chinese and a rich command of knowledge in culture as well as the ability of independent thinking can you enjoy the strong staying power in learning linguistics, literature and the like. Thus, you can be a real scholar in your field.

Mingyuan Gu's speech (2003, pp.18-19) includes the following: Elementary pupils must learn mother tongue well first. You can't develop thinking or intelligence without mastering your mother tongue first; your cultural quality will be affected and can't master your national relics in culture if you haven't learnt mother tongue well; you can't communicate smoothly between nationalities in your nation let alone the communication with other peoples in the world.

As is known, most well-known Chinese foreign-language-experts are great masters of their mother tongue, like Xun Lu, Zhongshu Qian are just a few. They are bilingual experts whose mother tongue---Chinese, is far superior to their second language, furthermore, they are famous for their Chinese works both at home and abroad. Therefore, we must realize clearly mother tongue is one of the cultural kernels and spirits of a nation in learning a second language. We must first and foremost teach children our mother tongue well. Otherwise, we'll take the branch for the root or without differentiating what is elementary from secondary.

\subsection{FLES in China and its language environment}

Many people think child's age in FLL is: "the younger, the better". In my understanding, there must be some special language environment. You know it's quite different for Chinese children and American minorities' to learn English. For example, if a Chinese couple moves to the USA, their children will have to learn English in school as the Americans do. These Chinese children have to face the natural language environment and culture of English and have enough chances to communicate and play with the people around them. Although English isn't their mother tongue, yet the Chinese children have to face everything encoded by it. Thus, they can think, speak and develop naturally in English. The natural language environment of English would assure them to master English naturally. But in China, the children can't have such an environment of English, and there's no natural communication in English for them. Therefore, the only way for them is to listen to more, to speak more, to practise more, to recite new words, language structures and grammar rules in English learning. This means that children's English learning in China is not natural or real English, but the transition of understanding Chinese and knowing English. And it's just a mixture of comparison from the two languages.

Obviously, it's natural for Chinese children to learn English as an L2 well in the USA, and "the younger, the better". But in China English is a foreign language for them, so it's a different matter totally, and "the younger in age, the more difficult in learning".

\section{Conclusion}

1) Concerning the problem of starting age in FLL, there's been no agreement in the past 50 years. Therefore, we should make people know the difficult situation of FLES worldwide and do what we could to get rid of the misunderstanding of idea "the younger, the better" in TEFL.

2) From the brief history of FLES in China, we are now repeating the same lesson taught in 1980s, especially in the backward areas, because of the same reason that lacks in qualified English teachers and the like. There are three kinds of viewpoints on FLES in China, but all of them agree on the one that qualified English teachers, suitable textbooks and adequate teaching equipment are the prerequisites in carrying out the decision of FLES. And this is what we need most now.

3) It is evident there's no "critical period" in TEFL for children anywhere in China. "Critical period hypothesis" only exists in natural language (mother tongue and L1) acquisition just as Lenneberg raised it in 1967.

However it doesn't mean children couldn't learn foreign languages. What we should do is to create a suitable bilingual environment, compile good textbooks, and use proper teaching methods according to children's psychology and physiology. Among all the factors, to train qualified foreign language teachers is the most important thing for them. What's more, the importance of one's mother tongue must be emphasized before any other language.

\section{References}

Beilei Wang. (2003). Is There an Optimal Age in FLL? Wai Yu Jie. Issue3. pp.33-38.

Chomsky. N. (1995). Chomsky's Linguistic Selections. Beijing: The Commercial Press. pp186, 212.

Chuming Wang. (2001). A Study on Age in Second Language Acquisition. The Research and Application of Chinese Linguistics. Shanghai: Shanghai Foreign Language Educational Press. Pp.100-115.

Dan Li. (1987). Children Developmental Psychology. Shanghai: East China Normal University Press. pp.119-159. 
Daoyi Liu. (2001). It should be careful in FLES. The Loose-leaf Selections of English for Middle and Primary Schools. Beijing: People's Education Press: Issue 8.

Ellis. R. (1999). The Study of Second Language Acquisition. Shanghai: Shanghai Foreign Language Education Press. pp.692-712.

Fathman. A.(1975). The Relationship between Age and Second Language Productive Ability. Language Learning. 25: pp. 245-253.

Guozhang Xu. (1992). Editor's Words---An Experiment in Shanghai. Foreign Language Teaching and Research. Issue 3. pp.1-2.

Huanqi Zuo.(2002). The Outlook of Foreign Language Education. Shanghai: East China Normal University Press.pp.36-40.

Jianzhong Zhang. (1996). English Pedagogy for Primary Schools. Taiyuan: Shanxi Higher Education Press.

Ke Fu. (1987). A History of Foreign Language Education in China. Shanghai: Shanghai Foreign Language Education Press. p.66.

Krashen. S. et al. (eds.). (1982). Child-adult Difference in Second Language Acquisition. Rowley. Mass: Newbury House. pp.120-129.

Lenneberg. E. (1982). Biological Foundation of Language. New York: Wiley. pP.66-78.

Lianrui Yang. (1998). On the Problems of Age in Foreign Language Education. Foreign Language Teaching Abroad. Issue2. pp. 28-30.

Mingyuan Gu. (2003) A Talk from Linguistic Function to Foreign Language Teaching in Primary School. Subject---Textbook---Teaching Method. Beijing: People's Education Press. Issue 6. pp.18-19.

Montessori M.(1993). Montessori's Scientific Methods in Education Children. Beijing: People's Education Press. pp. 425-429.

Naiqiang Yao. (1996). Master's Style. In Memory of Professor Guozhang Xu. Beijing: Foreign Language Teaching and Research Pres. P.155.

Nikolov. M. (2000). Issues in Research into Early Foreign Language Programmes. In Moon. J. \& Nikolov. M. (eds.) Research into Teaching English to Young Learners: International Perspectives. University of Pécs. pp.21-48.

Scovel. T. (1981). The Recognition of Foreign Accents in English and Its Implications for Psycholinguistic Theories of Language Acquisition in Savord and Laforge (eds.). pp.58-65.

Shichun Gui. (1987). Is the Earlier the Better in FLL? Foreign Language Teaching and Research. Issue 1. pp.56-57.

Shichun Gui. (1992). Doubt on Foreign Language Learning Must Be Started from an Earlier Age. Foreign Language Teaching and Research. Issue 4. pp.52-54.

Snow. C. \& Hoefnagel-Höhle. M. (1978). The Critical Age for Language Acquisition: Evidence from Second Language Learning. Child Development. 49: pp.1114-1128.

Stern. H. \& Weinrib. A. (1977). Foreign Languages for Younger Children: Trends and Assessment. Language Teaching and Linguistics: Abstracts. 10: p. 20.

Stern. H. (1999). Fundamental Concepts of Language Teaching. Shanghai: Shanghai Foreign Language Education Press. pp.366-367.

Wilkinson. L. (ed.) (1990). Communicating in the Classroom. New York: Academic Press. pp.38-45.

Xiaodong Liu. (2002). It's a Mistaken Trap if All the Children Go to Learn a Foreign Language in Swarms. Setting the Children Free. Xinhua Press. pp.31-40.

Xiongli Yang. (2001.11.21). Sudents Should Master Their Mother Tougue First. Wenhui Daily.

Zhengdong Zhang. (2001.3.1).The Policy Measures in Carrying out FLES. Beijing: Guang Ming Daily. 